\title{
Various history and physical examination characteristics predicted nerve root compression
}

Vroomen PC, de Krom MC, Wilmink JK, et al. Diagnostic value of history and physical examination in patients suspected of lumbosacral nerve root compression. J Neurol Neurosurg Psychiatry 2002;72:630-4.

\section{QUESTION: In patients presenting to a primary care physician with a new episode of pain radiating into the leg, how accurate are history and physical examination characteristics for detecting nerve root compression?}

\section{Design}

Blinded comparison of history and physical examination characteristics with magnetic resonance (MR) imaging. Source of funding:
not stated.

For correspondence: Dr P C Vroomen Hospital, Maastricht, the Netherlands.

por@sneu.azm.nl
Maastricht University

\section{Setting}

Neurology department of a university hospital in Maastricht, the Netherlands.

\section{Patients}

274 patients (mean age $46 \mathrm{y}, 51 \%$ men) with a new episode of pain radiating into the leg. Exclusion criteria
Independent history and physical examination predictors of nerve root compression on magnetic resonance imaging*

\begin{tabular}{|c|c|c|c|c|c|}
\hline $\begin{array}{l}\text { Predictors by history } \\
\text { exam }\end{array}$ & Sensitivity & Specificity & LR+ & LR- & $\begin{array}{l}\text { Adjusted OR }(95 \% \\
\text { CI) }\end{array}$ \\
\hline $\begin{array}{l}\text { Pain worse in leg than in } \\
\text { back }\end{array}$ & $82 \%$ & $54 \%$ & 1.78 & 0.33 & 4.5 (3.3 to 6.2$)$ \\
\hline $\begin{array}{l}\text { Typical dermatomal } \\
\text { distribution }\end{array}$ & $89 \%$ & $31 \%$ & 1.29 & 0.35 & $3.2(2.2$ to 4.7$)$ \\
\hline $\begin{array}{l}\text { Pain worse on coughing, } \\
\text { sneezing, or straining }\end{array}$ & $50 \%$ & $67 \%$ & 1.52 & 0.75 & 2.0 (1.4 to 2.7 ) \\
\hline \multicolumn{6}{|l|}{$\begin{array}{l}\text { Predictors by physical } \\
\text { examination }\end{array}$} \\
\hline Paresis & $27 \%$ & $93 \%$ & 3.86 & 0.78 & 5.2 (3.3 to 11.6$)$ \\
\hline $\begin{array}{l}\text { Finger floor distance }>25 \mathrm{~cm} \\
\qquad 00 \text { to } 4 \mathrm{~cm}\end{array}$ & $45 \%$ & $74 \%$ & 1.73 & 0.74 & 2.8 (1.9 to 4.3 ) \\
\hline
\end{tabular}

*Diagnostic terms defined in glossary; OR = odds ratio. Sensitivity, specificity, and LRs calculated using data in article and ORs derived using multiple logistic regression analysis. were previous spinal surgery, pregnancy, severe comorbidity, or contraindication to MR imaging.

Description of test and diagnostic standard Standardised methods were used to assess history and physical characteristics. The diagnostic standard was MR imaging of the lumbar spine within 24 hours after the clinical examination (including MR radiculography).

\section{Main outcome measures}

Independent history and physical examination predictors of nerve root compression on MR imaging using multiple logistic regression analysis, and predictive power of diagnostic models.

\section{Main results}

$56 \%$ of MR imaging studies detected root compression. Several history items and physical examination tests independently predicted nerve root compression (table). For a multivariate model including history and physical examination variables, the area under the receiver operating characteristic (ROC) curve was 0.83 ; for a model that included only history variables, the area under the ROC curve was 0.80 .

\section{Conclusion}

In patients presenting to a primary care physician with a new episode of severe pain radiating into the leg, history and physical examination characteristics predicted nerve root compression on magnetic resonance imaging.

\section{COMMENTARY}

The study by Vroomen $e t$ al focuses on a group of patients referred from primary care with sciatica severe enough that it might warrant 14 days of bed rest, which was incidentally shown to be ineffective. ${ }^{1}$ These criteria gave a high pre-test probability of disc herniation, with an associated rate of nerve root compression of $56 \%$. This should be interpreted against an underlying prevalence of lumbar disc herniations of $20 \%$ in asymptomatic persons $<40$ years of age and $27 \%$ in those $>40$ years of age. ${ }^{2}$

The area under the ROC curve describes the ability of a test to discriminate those with nerve root compression from those without compression. An area under the ROC curve of 1.0 represents a perfect test, whereas an area of 0.5 represents a worthless test (equivalent to tossing a coin). With an area under the ROC curve of 0.8 , history alone is in the "good" range. With the addition of physical examination, the area under the curve increases marginally to 0.83 . These findings are concordant with a previous study comparing history and examination with computed tomography scanning in the diagnosis of radicular leg pain. ${ }^{3}$

What is the point of physical examination and MR imaging when the history suggests radicular leg pain? Examination defines the extent of radiculopathy accompanying the radicular pain by seeking signs of nerve dysfunction. Decisions about management are based principally on history and examination, and not on radiological findings. The role of MR imaging is to define and locate the pathology. Given the favorable natural history of radicular pain within the first month ${ }^{4}$, MR imaging is justified only in a small proportion of those who fail to improve with time or have serious neurological deficits warranting surgical intervention or exclusion of rare but serious pathologies.

Michael Yelland, MBBS

University of Queensland, Herston, Queensland, Australia

1 Vroomen PC, de Krom MC, Wilmink JT, et al. Lack of effectiveness of bed rest for sciatica. New Engl J Med 1999;340:418-23.

Wiesel SW, Tsourmas N, Feffer HL, et al. A study of computer-assisted tomography. I. The incidence of positive CAT scans in an asymptomatic group of patients. Spine 1984;9:549-51.

Haldeman S, Shouka M, Robboy S. Computed tomography, electrodiagnostic and clinical findings in chronic workers' compensation patients with back and leg pain. Spine 1988; 13:345-50

Weber H, Holme I, Amlie E. The natural course of acute sciatica with nerve root symptoms in a double-blind placebo-controlled trial evaluating the effect of piroxicam. Spine 1993;18:1433-8 